Running head : MOTHER-CHILD JOINT WRITING

Mother-child Joint Writing in an Environmental Print Setting:

Relations with Emergent Literacy

Michelle M. Neumann, Michelle Hood \& Ruth M. Ford

School of Psychology, Griffith University, QLD 4222, Australia

Please direct correspondence to:

Michelle Neumann: School of Psychology, Gold Coast Campus, Griffith University, QLD 4222, Australia. E-mail: michelle.neumann@griffithuni.edu.au

Facsimile: +61(0)7 5552 8291, Telephone: +61(0)7 55528052 . 


\begin{abstract}
Mother-child dyads $(N=35)$ were videoed as they wrote a shopping list in an environmental print-rich grocery shop play setting. The children ( $M$ age $=4.3$ years $)$ were assessed on emergent literacy skills (letter name and sound knowledge, print concepts, phonological awareness, and letter and name writing). Mothers' general level of print and graphophonemic mediation during the joint writing task was scored. After controlling for child age, maternal print and grapho-phonemic mediation of children's writing were both positively related to letter-sound knowledge. Grapho-phonemic mediation was positively related to print concepts. A particular focus of this study was to investigate mothers' natural use of surrounding environmental print to scaffold writing. Only 4 mothers used environmental print to scaffold their child's writing. These mothers applied a variety of strategies including pointing out letters, describing letter shapes, and encouraging copying of letters and words from product labels and signs. There were no obvious differences between those who did or did not use environmental print in demographic factors, emergent literacy skills, or maternal mediation during joint writing. Despite there being only a small number of mothers who used environmental print, the range of strategies observed highlights the need for further research into using environmental print to scaffold children's emergent writing.
\end{abstract}

Keywords: environmental print, joint writing, emergent literacy, mother-child interactions, preschoolers 


\section{Mother-child Joint Writing in an Environmental Print Setting: Relations with Emergent Literacy}

Environmental print surrounds us daily and fulfils real-life functions (e.g., product labels and signs; Horner, 2005; Prior \& Gerard, 2004; Vukelich, Christie \& Enz, 2008). There is some evidence that it plays an important role in emergent literacy, especially in the home (Gerard, 2004; Miller, 1995; for a review see Neumann, Hood, Ford, \& Neumann, in press) as children explore and use it to gain meaning (Goodman, 1986; Harste, Burke, \& Woodward, 1981; Whitehurst \& Lonigan, 1998). Logographic reading (using visual cues rather than letter-sound analysis to decode words; Frith, 1985) of environmental print is also positively associated with emergent literacy skills such as print concepts, phoneme awareness, and alphabet knowledge (Lomax \& McGee, 1987; McGee, Lomax, \& Head, 1988). These emergent literacy skills are important predictors of future reading ability and long-term academic outcomes (e.g., Australian Government, 2005; Snow, Burns, \& Griffin, 1998).

Observational reports of parent-child interactions with environmental print have emphasized the important role that parents play in using this type of print to scaffold emergent literacy (Baghban, 1984; Campbell, 1998; Lass, 1982; Mason, 1980; McGee \& Richgels, 1989; Miller, 1995; Neumann, Hood, \& Neumann, 2009; Neumann \& Neumann, 2010; Purcell-Gates, 1996; Sinclair \& Golan, 2002). The term scaffolding (Wood, Bruner, \& Ross, 1976) refers to a parent's ability to sensitively provide their child with enough guidance to extend the child's movement within their zone of proximal development (Vygotsky, 1978). For example, Lass (1982) described how she pointed out and said the names of letters on street signs to her young son during their walks together after which he would identify them. McGee and Richgels (1989) reported how a father pointed out the K in K-mart. His daughter responded by saying, “I see a K, just like Kristen” (p. 221). Similarly, Neumann et al. (2009) 
described how a mother pointed out and traced letters on cereal box labels at breakfast time with her son. Parents are in an ideal position to draw their children's attention to environmental print that is attuned to their socio-cultural background, and respond to their child in ways that can support and extend their reading of environmental print (Gerard, 2004; Miller, 1995).

However, little is known about environmental print and emergent writing. Two case studies have examined parental use of environmental print to scaffold children's early writing (Neumann et al., 2009; Neumann \& Neumann, 2010). Neumann and Neumann (2010) reported how a mother pointed out environmental print to her child, saying the letter name and sound, traced these letter shapes with fingers, wrote letter shapes in the air with hands and used directional (up, down, around and across) and descriptive language (e.g., "That's a snakey SSSS" p. 82) to scaffold the writing of these letter shapes and words on paper. "Roseanna" responded positively to this approach by self-initiating her own writing using these strategies.

It is well established that a child's early writing experiences are important in early literacy development (e.g., Diamond, Gerde, \& Powell, 2008; Mayer, 2007; Ritchey, 2008; Stellakis \& Kondyli, 2004; Sulzby, Barnhart, \& Hieshima, 1989; Teale \& Sulzby, 1986). Across cultures, children's earliest scribbles or markings purposely convey meaning and contain universal features such as linearity and wavy lines (Levin \& Bus, 2003; Tolchinsky, 2003; Yamagata, 2007). However, learning to write requires an emerging understanding of symbolic representation and writing conventions that are specific to a child's language system (e.g., Puranik \& Lonigan, 2011). Baghban (2007) described the approximate timetable for early writing development specific to English alphabetic script. From 1 to 3 years children engage in random or localized scribbling. Between $1 \frac{1}{2}$ and 3 years they show controlled scribbling (e.g., dots, circles). They can write their own name between 4 and 6 years, at 
which point they also show linear expansions/labeling or captioning of drawings as well as pre-phonetic spelling (with no correspondence to sounds). Phonetic spelling (use of alphabetic consonant and vowel sounds) emerges between 4 and 7 years.

Emergent writing skills such as letter, name, and word writing are related to emergent literacy skills including alphabet knowledge (Bloodgood, 1999; Diamond et al., 2008; Hecht \& Close, 2002; Molfese, Beswick, Molnar \& Jacobi-Vessels et al., 2006; Ritchey, 2008; Welsch, Sullivan, \& Justice, 2003) and phonological awareness (Aram, 2006; Aram \& Biron, 2004; Aram \& Levin, 2001). The valuable role that parents play in supporting and shaping their children's early writing attempts by providing writing materials and opportunities to use them, giving feedback about writing attempts, and extending and clarifying writing interactions through sensitive mediation are well-established in preschool-aged children (Aram, 2002, 2007, 2010; Aram \& Levin, 2001, 2002; Burns \& Casbergue, 1992; DeBaryshe, Buell, \& Binder, 1996; Green, 1987; Stellakis \& Kondyli, 2004; Yang \& Noel, 2006).

For example, Baghban (1984) describes a longitudinal case study of her child 'Giti' from birth to 3 years of age during which time her emergent scribbles, drawing, and writing were encouraged and scaffolded by her mother. Bloodgood (1999) observed a parent of a 2year-old guiding his name writing attempts by providing an example and holding his hand to trace. Pinto, Accorti Gamannossi, and Cameron (2011) observed joint drawing interactions in seven 30-month-old children and their families in seven countries (Thailand, Peru, Italy, Canada, UK and Turkey). They found that across cultures children's early drawing interactions consisted of similar features such as shared adult-child attention and presence of drawing materials in homes. Pinto et al. also described how parents use playful drawing interactions to teach their children about print. For example, they describe how a Turkish father drew a BMW logo and then asked his daughters, "What is this?" His daughters 
whispered back the names of the letters to him. Other studies that have focused more on specific joint writing tasks (e.g., writing a letter; Burns \& Casbergue, 1992) have shown parents modeling words for their child to copy and dictating letter names in a warm and affectionate way (Aram \& Levin, 2001).

The benefits of mother-child joint writing in enhancing emergent literacy skill development and predicting long-term benefits to conventional literacy skills has been shown in a number of studies by Aram and colleagues. For example, Aram and Levin $(2001 ; 2002)$ examined mothers' scaffolding strategies (e.g., word segmenting, retrieval of letter shapes, and printing) during joint writing activities with their kindergarten children and found that mediation in joint writing activities was strongly linked to word writing and recognition and phonological awareness. Aram and Levin (2004) followed up these participants $2 \frac{1}{2}$ years later and evaluated their spelling, reading comprehension, and linguistic skills in Grade 2. The quality of maternal writing mediation in kindergarten predicted these literacy measures, after controlling for differences in SES. This highlights the significance of early joint writing experiences in emergent literacy development.

In a recent intervention study, Levin and Aram (2010) coached mothers to mediate their child's learning of writing (using a commercial kit of magnetic letter/word games for enhancing letter knowledge and writing words that start with a specific letter sound), storybook reading (using open-ended questions during shared reading), or visuomotor skills (cutting and gluing activities), and assessed the effects on emergent literacy. Maternal mediation of writing was the most effective in promoting alphabet knowledge (letter name and sound), phonological awareness, word spelling, and decoding. Levin and Aram further suggested that joint writing activities could be made more fun and enjoyable for parents and children by encouraging them to engage in a range of home-writing activities such as writing friends' names on birthday invitations, a note to grandparents, or a grocery list. 
To our knowledge, no studies beyond case studies (e.g., Baghban, 1984; Neumann, et al., 2009; Neumann \& Neumann, 2010) have investigated to what extent mothers naturally utilize surrounding environmental print to scaffold children's early writing. Environmental print is meaningful and functional and could be used in everyday joint-writing activities like writing shopping lists. Furthermore, the relationship between maternal print mediation using environmental print and emergent literacy skills has not been investigated in a larger sample. Another current limitation, is that most of the joint-writing studies come from one group (Aram and colleagues) working with Hebrew script, which differs to the English alphabetic script. For example, Hebrew is written from right to left and consists of 22 letters with 5 changing form when placed at the end of a word. English is written from left to write, and consists of 26 letters. Therefore, further research is needed to determine if the maternal strategies already noted generalize to the English alphabetic script.

To explore this, the present study used observational methods within a grocery shop play setting to examine how mothers self-initiate a strategy of using salient environmental print to scaffold their child's writing in a joint writing activity (i.e., writing a shopping list). Environmental print settings provide a social context where literacy behaviors naturally occur and have been designed and used by researchers to replicate literacy contexts from the outside world (Neuman \& Roskos, 1993; Vukelich, 1994). An advantage of the observational method is that it provides realistic data on how mother-child dyads naturally interact with environmental print when completing a joint writing task as opposed to parent questionnaires which are subject to social desirability bias (Dodici, Draper \& Peterson, 2003).

More broadly, this study examined the general types of joint writing strategies mothers used. It also investigated the relationship between maternal print mediation (maternal scaffolding of written letter formation; Aram, 2002) and grapho-phonemic mediation (maternal scaffolding of letter-sound connections during word writing; Aram, 2002) and 
children's emergent literacy skills. It was expected that maternal print and grapho-phonemic mediation during the joint writing task would be positively associated with emergent literacy skills. As the extent to which mothers would naturally use environmental print was unknown, no specific predictions regarding this were made. Finally, this study examined maternal print mediation in a sample of native English-speaking Australian mother-child dyads. This allowed previous results obtained with Hebrew (e.g., Aram \& Levin, 2001; 2002) to be extended to English writing.

\section{Method}

\section{Participants}

The sample comprised 35 mother-child dyads recruited from six childcare centres on the Gold Coast in Queensland, Australia. The preschool children (43\% boys; $57 \%$ girls) had a mean age of 4.3 years $(S D=.47$; range $=3.36-4.98$ years $)$. Children who had known developmental problems or for whom English was not their main language (reported by parents on a parent demographic questionnaire) were excluded. Children were also excluded if they had a standard score below 80 on the Peabody Picture Vocabulary Test $4^{\text {th }}$ Edition (PPVT-IV, Dunn \& Dunn, 2007) to ensure average language development. Three children for whom consent was obtained were excluded based on these criteria.

Most mothers were married or in a de facto relationship (91.4\%), $2.9 \%$ were divorced or separated, and $5.7 \%$ were never married or in a de facto relationship. The percentage of mothers in each education level were: $10^{\text {th }}$ or $11^{\text {th }}$ grade $(5.7 \%)$, high school graduate (14.3\%), partial college or specialized training (25.7\%), standard college or university degree (37.1\%), and graduate professional training (17.1\%). The family socio-economic status (SES) was calculated using the Hollingshead 4-factor Index (Hollingshead, 1975). The mean fell in the middle SES range from 40 to $54(M=51.26 ; S D=8.18$; Range 34 - 63). 
Most children (23) were first-born, nine were second-born, two third-born, and one child was fifth-born. Most children (21) had one sibling, eight had no siblings, five had two siblings, and one child had four siblings. Most children lived with both parents (77.1\%) and one child lived with only their mother. The remainder (7) lived with three or four adults in their family.

\section{Procedure}

Ethics approval was obtained from the university research ethics committee. Permission was gained from the directors of the six childcare centers and written informed consent to participate was obtained from mothers. Eligible children were assessed in a quiet room at their centres on the emergent literacy measures (letter name and sound knowledge, print concepts, phonological awareness, name and letter writing). Children were thanked with stickers at the completion of the assessments. On the same day, each mother and child dyad completed the joint writing task (a shopping list) in a grocery shop play setting.

\section{Joint writing task.}

Mothers and children played for 15 minutes in a grocery shop setting in which they were able to handle the environmental print items immediately prior to the joint writing task. The play in the grocery shop setting that occurred prior to the writing task enabled mothers and children to gain exposure to the print and become familiar with the setting. Mothers were instructed to "Please play naturally with your child for 15 minutes in this grocery shop play setting". For the joint writing task, each mother-child dyad was asked to sit side-by-side at the table in the grocery shop setting. Mothers were then instructed "Now we will do something different. I want you to help your child write some words so you are going to help your child write a shopping list. I want your child to do the writing but you can help in any way you like. The first word I want you to help your child to write is lollipop. The next word 
I want you to help your child write is icecream. Please help your child write more words on your shopping list if you have time. I'll give you five minutes to write." A blank sheet of A4 paper and one pencil was placed on the table in front of the child. As noted earlier, mothers and children were not prompted in any way to use the environmental print items on the surrounding shelves as we were interested in the extent to which this would occur spontaneously. The researcher remained in the room to video the joint writing task and sat behind the video recorder.

\section{Materials}

A small corner of a room was fitted with grocery shop props (e.g., cash register), grocery items (e.g., cereal boxes, icecream box, lollipop packet), and signs (e.g., EXIT, GROCERY SHOP, OPEN/CLOSED), as well as a small table and chairs for the joint writing activity. Figure 1 illustrates examples of the environmental print rich grocery items.

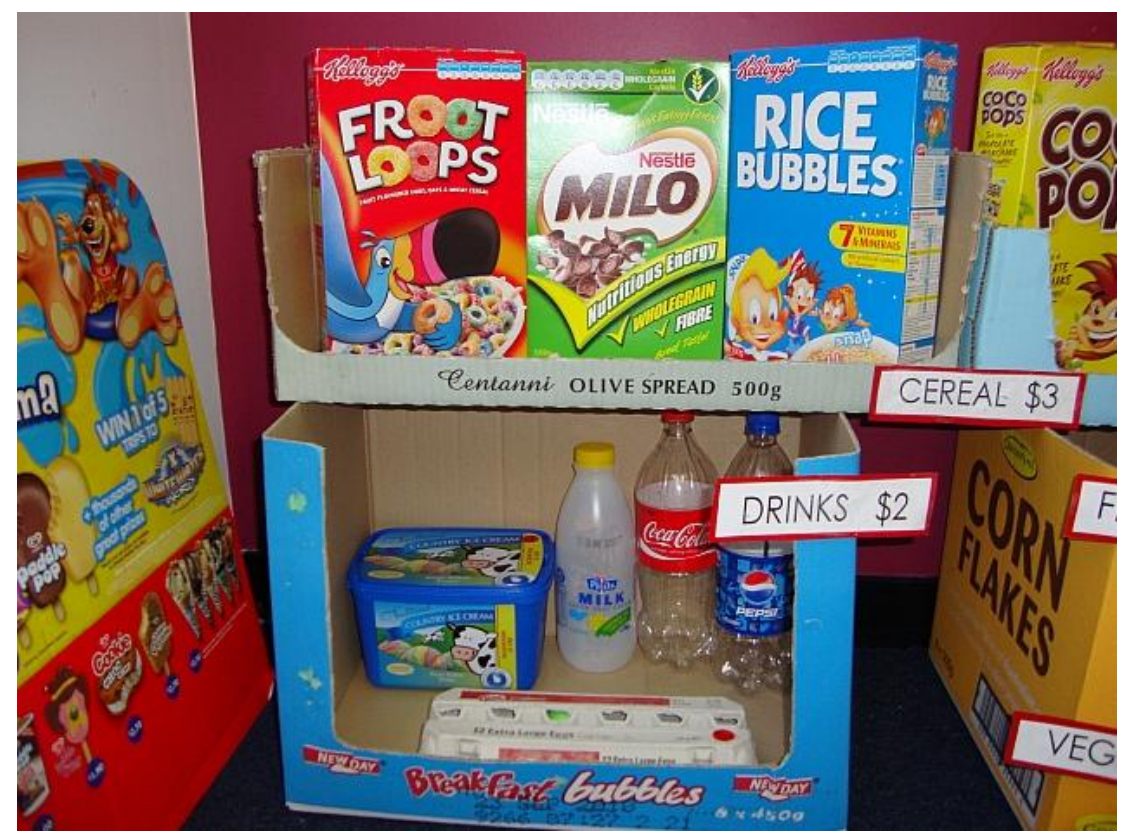

Figure 1. Environmental print products and signs in the grocery shop setting.

Measures 


\section{Joint writing}

Maternal behaviors during the joint writing task were coded using an established scale adapted from Aram $(2002,2007,2010)$ and Aram and Levin $(2001,2002)$ for maternal print mediation (maternal scaffolding of letter shaping; see Table 1) and grapho-phonemic mediation (maternal scaffolding of letter-sound connections; see Table 2). Maternal print mediation was scored on a scale of 0 to 4 (see Table 1) for each letter in the given words (lollipop and icecream) written by the child. An average score was computed across the number of letters the child had written. Each letter produced in each word was also scored on a scale of 0 to 7 for grapho-phonemic mediation (Table 2) and an average score computed. In addition, as pointed out by Aram $(2007,2010)$ the highest level of the mediation scales (print mediation: mother encourages the child to form the letter on their own, and grapho-phonemic mediation: mother encourages the child to write the correct letter on their own) reflects active monitoring and guidance by the mother that enables the child to print letters and encode words independently.

Scoring of environmental print use refers to any use during the joint writing task. Mothers scored 1 point for using environmental print in the grocery shop setting to scaffold writing (no use, score $=0$ ). The environmental print strategies used by mothers were transcribed and described qualitatively. 
Table 1

Print Mediation Scale (Maternal Scaffolding of Letter Shaping)

\begin{tabular}{lc}
\hline Behavior & Point scale \\
\hline Mother allows child to scribble randomly or write their own letters. & 0 \\
$\begin{array}{l}\text { Mother holds/guides the child's hand to shape the letter or helps the child trace } \\
\text { letters by doing dots in shape of letter. }\end{array}$ & 1 \\
Mother writes a letter then the child copies it. & 2 \\
$\begin{array}{l}\text { Mother scaffolds the child's letter shaping verbally as the child writes the letter } \\
\text { (e.g.." } M \text { goes up, down, up, down"; "H has } 2 \text { sticks in it"; "it's just like in your } \\
\text { name", mother traces letter on the page with a finger, or mother writes it in the } \\
\text { air). }\end{array}$ & 3 \\
$\begin{array}{l}\text { Child shapes the letter correctly on his/her own with the mother's } \\
\text { encouragement. }\end{array}$ & 4 \\
\hline
\end{tabular}

Table 2

Grapho-phonemic Mediation Scale (Maternal Scaffolding of Letter Sound Connections)

Maternal Behavior

Point scale

Mother allows the child to scribble randomly or write their own letters.

0

Mother holds/guides the child's hand to write the letter (silently and does not say

letter name) or does dots for child to trace letter.

Mother writes the letter for the child to copy (mother writes the word silently and child copies below).

Mother dictates the letter name as the child writes it.

Mother retrieves a phonological unit (phoneme/letter sound) then immediately dictates the required letter name then the child writes it down.

Mother retrieves a phonological unit (phoneme/letter sound) and encourages/helps the child link the phoneme with the letter name (child may or may not give the wrong answer first then with help says the correct letter name).

Mother encourages the child to retrieve a phonological unit (phoneme/letter sound) and helps the child link it to the letter name but does not provide letter sound or name. (e.g., M: "what do you hear next? Listen carefully to the sound". C: $L$ (child says letter sound). M: "How do we write it?" $C: L$ (child says letter name). Then child writes it down.

Child retrieves and writes the correct letter sound/name on his/her own with mother's encouragement. 
The first author initially scored all of the 35 joint-writing sessions. Then inter-rater reliability between two judges (the first author and a trained research assistant) was computed on the scoring of the print and grapho-phonemic maternal mediation of each of the written letters from a random selection of $28 \%$ of the sample $(n=10 ; 5$ boys and 5 girls; this equal gender split occurred by chance). This selection is comparable to other joint writing studies that have randomly selected $20 \%$ of their sample for inter-rater reliability (Aram, 2002; Aram \& Levin, 2002). Inter-rater reliability for maternal print mediation and maternal graphophonemic mediation was .96 and .98 , respectively. Following discussion and agreement on the inter-rater scores, and because the scores were similar, the first author's were used.

Letter name and sound knowledge. Children were presented with 26 upper-case letters printed in black Century Gothic font size 72 on individual 8 x $8 \mathrm{~cm}$ white cards. These were presented in random order. Children were asked to name the letter and provide its sound. A score of one point was given for each correct answer $(\max =26$ each for letter name and sound knowledge).

Print concepts. Clay's Concepts about Print test (2005) was administered by reading a storybook (Stones; Clay, 2008) to the child while asking questions about print concepts (e.g., point to where to start reading, point to a little letter). Children scored 1 point for each correct response and these were summed for a total print concepts score. There are acceptable split half reliabilities (0.84 - 0.89) and validity (0.64 - 0.79; Brassard \& Boehm, 2007). In the current study, only 9 of the 20 questions used showed acceptable internal consistency (Cronbach's $\alpha=.71)$, so only these 9 were retained in the final total score $(\max =9)$.

Phonological awareness. Phonological awareness was assessed using three tests. In the rhyme detection test (based on Muter, Hulme, Snowling, \& Taylor, 1997), four words (one target and three others) were presented in picture form while the examiner named them. 
The child was asked to point to one of the three pictures (e.g., car, table, bear) that rhymed with or sounded like the target picture (e.g., chair). There were 10 trials and children scored 1 for each correct response $(\max =10)$. Two practice items were provided with corrective feedback on these trials only.

The initial and final phoneme detection tests (based on Bowey, 1994) used similar methodology. Four words ( 1 target and 3 choices) were presented in picture form while the examiner named them. Children were asked to pick the word that started with the same sound as the target word (initial phoneme; e.g., bed and brush) or ended with the same sound (final phoneme; e.g., leg and pig). There were 2 practice trials for each test that included corrective feedback followed by 10 trials $(\max =10)$. A total score for phonological awareness out of 30 was obtained by combining the rhyme and initial and final phoneme scores. Cronbach's $\alpha$ was .75, indicating acceptable internal reliability. The phonological awareness scores were not adjusted for guessing.

Writing. Each child was asked to write their name first then all the letters they knew and could generate on their own in 60 seconds. Name writing was scored using a 7-point scale adapted from Bloodgood (1999) and Welsch et al. (2003; $0=$ No production e.g., child refuses to write; 1 = Random scribbling; 2 = Controlled and/or linear scribbling with no discernible letters present; 3 = Random letter-like forms; 4 = Strings of conventionally written random letters in linear patterns or the first letter of their name; $5=$ Name writing consisting of some correct letters; $6=$ Name writing is generally correct and some letters may be written backwards; 7 = Name written and spelled correctly).

For letter writing, each correctly written letter was given one point (upper and lower case of the same letter were given one point each but repeated letters were counted once only). Controlled and/or linear scribbling such as drawings, dots, circles, lines with no 
discernible letters present and random letter-like forms oriented incorrectly or back to front (i.e., pseudo-letters) were scored as zero. The number of conventional letters written was tallied to give a total letter writing score.

Receptive vocabulary. The PPVT-IV (Dunn \& Dunn, 2007) measures receptive vocabulary. The child selects one of four pictures that best represents a word spoken by the examiner. Dunn and Dunn reported split-half reliabilities of around .94.

\section{Results}

\section{General Maternal Print Mediation Strategies}

Table 3 presents the percentages of mothers who engaged in each print mediation behavior to scaffold the child's writing of lollipop and icecream. Very few mothers allowed their child to randomly scribble. The most commonly observed behavior was the mothers using verbal and interactive scaffolding strategies (42.9\%). Nearly half of the mothers engaged in this. Approximately one third of mothers wrote letters for their child to copy. A small percentage of mothers made dots in the shape of the letter on the page for their child to trace over or held the child's hand/wrist to guide the child's formation of more difficult letter shapes. Very few children independently formed letters.

A wide range of verbal strategies that used descriptive or directional language to scaffold letter shaping were observed in 15 mothers. Descriptions were personally relevant to the child and linked the letter shape to the shape of common objects; for example, "P looks like a lollipop"; " $\mathrm{m}$ is like two bridges or two mountains". Other maternal descriptions focused on letter shapes; for example, "a is like a circle with a stick", "c is a half a circle; " $\mathrm{i}$ is a line with a dot". Other descriptions referred to a letter as a combination of shape and other letter or number names; for example, "P has a big long line like a 1, and a half a circle on 
top"; "O is a zero", "y is a u with a tail". Mothers also referred the child to a personal word they already knew that contained the target letter. Generally, the reference was to their own or to other children's names; for example, "E like in your friend Eva" or "c like in Jack".

Directional language (up, down, around and across) also helped children shape letters. For example, "c goes around and stops"; "e goes across and around", "l goes down” and 'M goes up and down". One mother said, "p goes up and a little bit around" as she drew it in the air with her finger. Of the 15 mothers, 13 used a combination of descriptive and directional language for example, "e goes in the middle and around with a tail"; "P goes down with a circle attached".

Table 3

Percent of Mothers Engaging in each Print Mediation Behavior

Behavior Percent

Mother allows child to scribble randomly or write their own letters.

$11.4 \%$

Mother holds/guides the child's hand to shape the letter or helps the child trace letters by doing dots in shape of letter.

Mother writes a letter then the child copies it.

Mother scaffolds the child's letter shaping verbally as the child writes the $42.9 \%$ letter (e.g.," $M$ goes up, down, up, down"; "H has 2 sticks in it"; "it's just like in your name", mother traces letter on the page with a finger, or mother writes it in the air).

Child shapes the letter correctly on his/her own with the mother's encouragement.

\section{General Maternal Grapho-phonemic Mediation Strategies}

Table 4 presents the percentages of mothers who engaged in each grapho-phonemic mediation behavior. Again, very few mothers allowed their child to scribble randomly or write letters unrelated to the target words. The most commonly observed behavior, seen in 
around two thirds of mothers $(68 \%)$ was the mother dictating the letter names for the child to write the word. There was little use of phonological strategies. A small percentage of mothers retrieved a phoneme/letter sound but immediately dictated the required letter name. No mothers were observed encouraging the child to utilize the phonological representation independently in order to write the grapheme.

Letter names were often associated with a word or name that was personally meaningful to the child. Some mothers would also emphasize the initial letter sound in the associated word (e.g., "like M for MMMadison"). Other mothers said the letter name then linked it with a word beginning with the same letter sound such as $\mathrm{p}$ for puppy, o for octopus; $r$ for rabbit. This was extended by the mother asking their child what else began with that letter. For example, one mother said, "e for Ethan, what other words start with e?" The child replied, "Elisha".

Interestingly, two mothers encouraged their child to write the next letters in the words and praised their child even though the letters were incorrect. For example, a mother prompted her daughter to complete the word icecream and said "Icecream, what can you hear at the end?" The child replied "buh" and the mother said, "OK write it down". The child wrote the letter $b$, and the mother said, "Beautiful". Then she ran her finger under each of her child's words, saying "lollipop" and "icecream", even though the child's words did not resemble those words. Another mother allowed her daughter to write whatever letters she wished for each word. Although the child was shaping letters conventionally, they were strings of recurring random letters with no association to the required word. The mother praised the child after she wrote each of her "words". These mothers appeared to display sensitivity to their child's writing attempts and encouraged them; however, they did not extend their child's grapho-phonemic knowledge during these interactions. 
Table 4

Percent of Mothers Engaging in each Grapho-phonemic Mediation Behavior

Maternal Behavior

Percent

Mother allows the child to scribble randomly or write their own letters.

Mother holds/guides the child's hand to write the letter (silently and does not say letter name) or does dots for child to trace letter.

Mother writes the letter for the child to copy (mother writes the word silently and child copies below).

Mother dictates the letter name as the child writes it.

Mother retrieves a phonological unit (phoneme/letter sound) then

immediately dictates the required letter name then the child writes it down.

Mother retrieves a phonological unit (phoneme/letter sound) and encourages/helps the child link the phoneme with the letter name (child may or may not give the wrong answer first then with help says the correct letter name).

Mother encourages the child to retrieve a phonological unit (phoneme/letter sound) and helps the child link it to the letter name but does not provide letter sound or name. (e.g., M: "what do you hear next? Listen carefully to the sound". C: $L$ (child says letter sound). M: "How do we write it?" $C$ : $L$ (child says letter name). Then child writes it down.

Child retrieves and writes the correct letter sound/name on his/her own with mother's encouragement.

\section{Relationships Between Joint Writing Mediation and Emergent Literacy}

Letter name knowledge, print concepts, phonological awareness, name writing, maternal print and grapho-phonemic mediation were all normally distributed. Letter sound knowledge and letter writing were both positively skewed. Square-root transformations resulted in normal distributions. The descriptive statistics are shown in Table 5. The mean maternal print mediation score approximates to verbal scaffolding of the letter shape (e.g., L 
goes down and across). The mean maternal grapho-phonemic score approximates to mothers dictating letter names as the child wrote each letter. The maximum score achieved in graphophonemic mediation indicates that mothers were generally mechanically assisting their child to write rather than encouraging their child to retrieve letter sounds. More letter names than sounds were known; however, there was a wide range in children's letter knowledge. While some children knew all the letter names, no child knew all 26 letter sounds. There was also much variability in children's phonological awareness, with all children showing some awareness of the phonological units assessed. On average, the children had some knowledge of print concepts (e.g., book handling, directionality, and letter and word concepts such as what a capital letter is). However, again there was wide variability with some children not showing any of these concepts and some at ceiling. On average, the children could independently write between three and four letters and some letters in their name, especially the first letter. The mean receptive vocabulary (screening measure) score was within the "Average" range, with a range from "Low Average" to "Superior".

Table 5

Descriptive Statistics for Maternal Print Mediation and Child Emergent Literacy Skills

\begin{tabular}{llll}
\hline Measure & Mean & $S D$ & Range \\
\hline Print mediation $(\max =4)$ & 2.75 & 1.13 & $0-4$ \\
Grapho-phonemic mediation $(\max =7)$ & 2.89 & 1.01 & $0-4.88$ \\
Letter name $(\max =26)$ & 11.40 & 9.40 & $0-26$ \\
Letter sound $(\max =26)$ & 3.49 & 5.07 & $0-22$ \\
Print concepts $(\max =9)$ & 3.66 & 1.94 & $0-9$ \\
Phonological awareness $(\max =30)$ & 12.03 & 5.02 & $5-23$ \\
Name writing $(\max =7)$ & 4.71 & 2.23 & $1-7$ \\
Letter writing & 3.65 & 4.35 & $0-15$ \\
Receptive vocabulary $($ standardized score) & 106.51 & 10.30 & $84-130$ \\
\hline
\end{tabular}


Bivariate correlation analysis was used to explore the relationships between maternal print and grapho-phonemic mediation in the environmental print setting and emergent literacy skills. A 1-tailed test of significance was used because it was expected that mothers who provided higher levels of mediation during joint writing would have children with higher emergent literacy skills. Preliminary analysis showed that age was significantly correlated with all emergent literacy measures so the variance it explained was partialled out of subsequent analyses.

Table 6 presents the partial bivariate correlations between maternal print mediation and emergent literacy skills, with age controlled. There was a strong correlation between maternal print mediation and grapho-phonemic mediation, with $44.89 \%$ of the variance overlapping between these two measures. Each of these was significantly positively associated with letter-sound knowledge, accounting for around $10 \%$ of the variance in that aspect of emergent literacy. Therefore, a higher level of scaffolding during the joint-writing task was associated with greater child letter-sound knowledge. Only grapho-phonemic mediation was significantly positively correlated with print concepts, accounting for $9 \%$ of that variance. In contrast, maternal print and grapho-phonemic mediation were not significantly related to letter name knowledge, phonological awareness, or child letter and name writing. 
Table 6

Partial Correlations Between Maternal Print and Grapho-phonemic Mediation and

Emergent Literacy Skills, Controlling for Age.

\begin{tabular}{|c|c|c|c|c|c|c|c|c|}
\hline Variable & 1 & 2 & 3 & 4 & 5 & 6 & 7 & 8 \\
\hline 1. Letter Name & - & & & & & & & \\
\hline 2. Letter Sound ${ }^{a}$ & $.52^{* *}$ & - & & & & & & \\
\hline 3. Print Concepts & -.04 & .15 & - & & & & & \\
\hline 4. Phonological Awareness & .17 & $.58^{* *}$ & -.09 & - & & & & \\
\hline 5. Name Writing & .23 & .14 & .15 & -.03 & - & & & \\
\hline 6. Letter Writing ${ }^{\mathrm{a}}$ & .15 & .08 & .05 & -.05 & $.72^{* *}$ & - & & \\
\hline 7. Maternal Print Mediation & .19 & $.29^{*}$ & .21 & .17 & .08 & .13 & - & \\
\hline $\begin{array}{l}\text { 8. Maternal Grapho-phonemic } \\
\text { Mediation }\end{array}$ & .02 & $.34^{*}$ & $.30^{*}$ & .16 & .05 & .18 & $.67^{* *}$ & - \\
\hline
\end{tabular}

Note. 1-tailed $* p<.05 ; * * p<.01,{ }^{\mathrm{a}}$ Square root transformed

\section{Maternal Use of Environmental Print to Scaffold Writing}

Only four mothers (11.4\%) spontaneously used environmental print to scaffold their child's writing of letters and words. These mothers used environmental print to help their child identify and copy letters and words. This was observed to engage their children's interest and to provide rich opportunities for mother-child interactions about print during the joint writing task. The mother-child interactions that used environmental print are described below, with corresponding writing samples provided in Figure 2. In Figures $2 a$ and $2 b$ the 3year-old children required mechanical assistance for printing letters (e.g., drawing dots for the child to trace or holding their hand to shape a letter) and these mothers did not use phonemes to mediate writing. In Figure 2c the mother scaffolded the child's letter shaping verbally (e.g., "you have to draw a stick and a circle at the top") and dictated the letter names. 
In Figure $2 \mathrm{~d}$ the child was able to shape her letters correctly with her mother's encouragement and the highest level of grapho-phonemic mediation observed was maternal dictation of letter names.

Mother and son aged 3.43 years (see Figure 2a)

[The mother retrieved the lollipop packet from the grocery shop shelf and pointed to the word lollipop on the packaging to her child]

Mother: "What's that?"

[The child looked at the label]

Child: "Lollipop".

[The mother pointed to the word lollipop again and the child looked at it]

Mother: "What if we write a shopping list and we'll put lollipop on our shopping list?"

[The mother placed the lollipop packet back on the grocery shop shelf.

Then the child wanted to draw a picture of a lollipop. The mother retrieved the packet again and they looked at the picture of it on the packet]

Mother: "It's a circle shape"

Child: "It has a stick".

[The child drew pictures of lollipops. The mother pointed to the word lollipop on the packaging again]

Mother: "Look can you see that word there, it says lollipop. Do you want to try and write it? I'll do some dots and you can trace them".

[The child did not trace over the mother's dotted letters].

[The mother asked the child to draw an icecream and then she retrieved the icecream product from the shelf].

Mother: "What does the icecream look like in this picture?"

Child: "It looks like a hot air balloon".

[The mother pointed to the word icecream on the label]

Mother: "Do you know what that says there?"

[The child looked at the label]. 
Mother: "Ice".

Child: "Ice".

[The mother pointed to the next word]

Mother: "Do you know what that word says there?"

Child: "Icecream".

Mother: "You are so clever".

[The mother made dots for the word icecream for the child to trace. The child traced over the dotted letters i,c,e with his pencil, but then scribbled over it].

Mother and son aged 3.91 years (see Figure 2b):

[The mother pointed to the icecream product]

Mother: "Do we need some icecream then?"

[The mother pointed to the letters on the icecream lid]

Mother: "Can you copy these letters for me?"

[The mother pointed to the letters on the lid again]

Mother: "See those letters there?"

Child: "Yes".

Mother: "Can you copy that?"

Child: "No".

[The mother pointed to the letters again]

Mother: "Can you write icecream, we need some of these letters".

[The mother pointed to the I on the icecream lid]

Mother: "I, like this one".

[The child looked at the 'I' on the lid]

Child: "I".

[The child began to copy the letter I].

Mother: "straight down". (As the child wrote the 'I') 
[The child pointed to the $\mathrm{C}$ with his finger then copied it by himself. The mother pointed to the E].

Mother: "We need an E so we know its ice".

Child: "I don't know how to draw that one".

Mother: "OK well you hold the pencil and I'll show you".

[The mother then helped the child write rest of letters $\mathrm{c}, \mathrm{r}, \mathrm{e}, \mathrm{a}, \mathrm{m}$ without referring to the environmental print by holding his hand to form the letters; and while the mother said each letter name in the word the child spontaneously sang the alphabet song].

Mother and daughter aged 4.59 years (see Figure 2c):

[To help her child shape the $\mathrm{P}$ in lollipop the mother pointed to the letter $\mathrm{P}$ in the sign "GROCERY SHOP" for the child to see].

Mother: "Look at the shop, see the word SHOP on the wall, look at the word on the wall see the P or see the Paddlepop, we need to write pop, see the letter P".

[The child then wrote the letter $p$ in her word lollipop].

A mother with daughter aged 4.77 years (see Figure 2d) dictated the name of each letter in the words lollipop and icecream then encouraged her child to copy words from the cereal boxes. The mother pointed to the letter $\mathrm{C}$ on the COCO POPS box situated on the grocery shelf and the child copied each letter from the label. The mother also pointed out the word CORNFLAKES then dictated the letter names for her to write. The child formed her letters in mostly upper case form and did not use letter sounds or spell any words independently.

$t$-tests were conducted to compare mothers who did $(n=4)$ and did not $(n=31)$ use environmental print to scaffold children's writing on maternal print and grapho-phonemic mediation, emergent literacy skills, child age, and SES . There were no significant differences on any variables. 


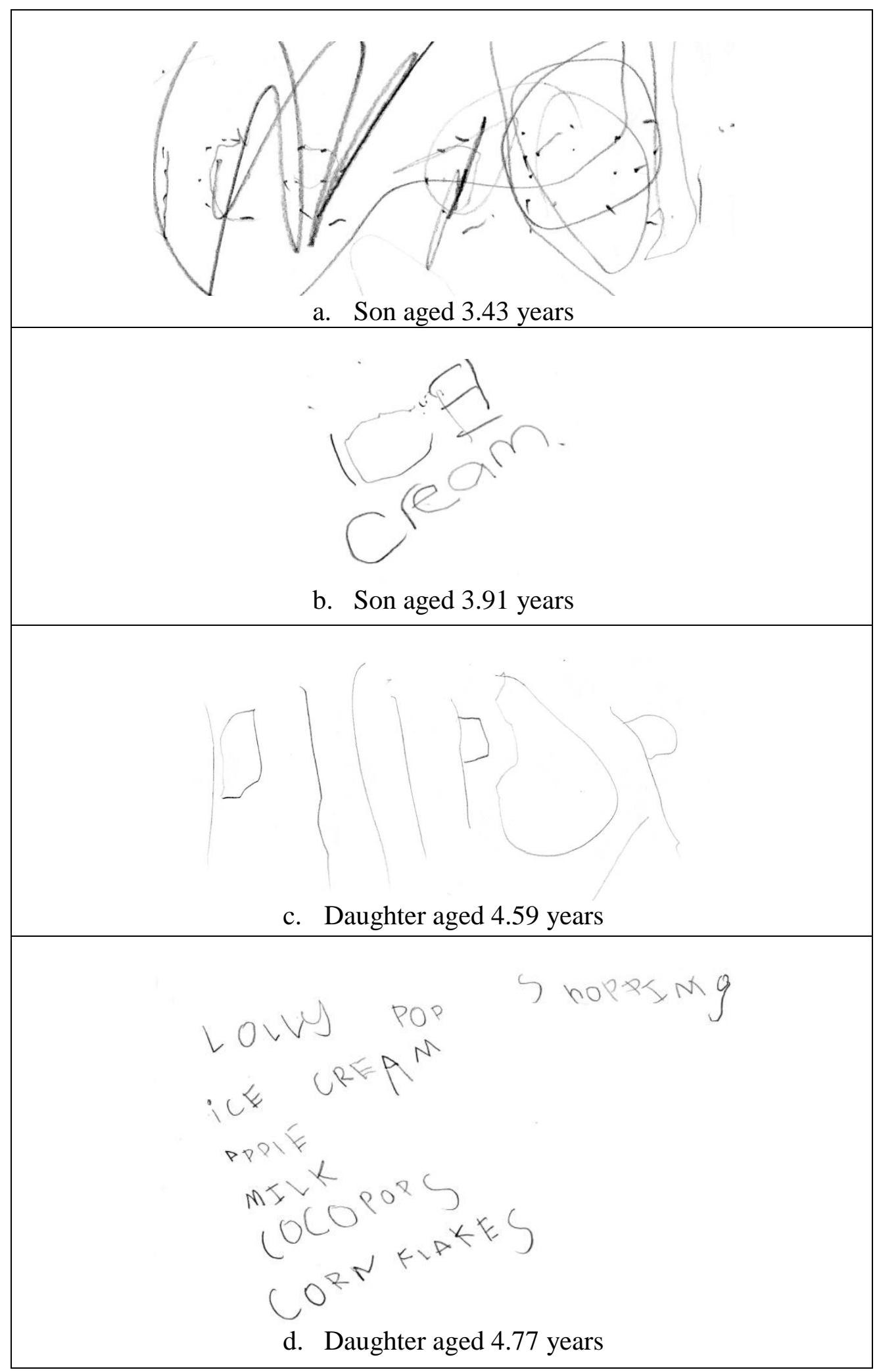

Figure 2. Children's writing samples where mothers used environmental print to scaffold their child's writing. 


\section{Discussion}

The present study extended previous research by examining joint writing in Australian English speaking mother-child dyads. We also explored how mothers naturally use environmental print to scaffold their child's writing. Although only a few mothers utilized environmental print they were observed using a variety of strategies resulting in rich print interactions. No differences were found between mothers who did and did not use environmental print on maternal mediation, child literacy skills, or demographic factors. We also examined the relationship between general maternal mediation of preschoolers' writing in an environmental print rich setting and children's emergent literacy skills. Of the emergent literacy skills assessed, only letter sound knowledge and print concepts were predicted by general maternal mediation strategies.

\section{General maternal mediation}

In the present study, mothers displayed a range of mediation strategies to scaffold their child's writing in the environmental print setting. The strategies observed for print mediation included descriptive (e.g., m looks like a seagull in the sky) and directional language ('e' goes across and around) to help scaffold letter shaping. Mothers also linked letter names to common words the child knew (e.g., p for papa). These findings replicate those reported in previous research. For example, Aram (2010) described how parents used descriptive language to describe letters (e.g., this letter looks like a circle) or words children already knew (e.g., it's the first letter of your name) in order to scaffold children's printing and used the initial letter names of words the child already knew to scaffold word writing.

We were also interested in the relationship between maternal print and graphophonemic mediation within an environmental print-rich setting and children's emergent literacy skills. Maternal print mediation and grapho-phonemic scores were both positively 
associated with children's letter-sound knowledge. Although speculative this suggests that the level of scaffolding mothers provided for letter shaping (e.g., using directional and descriptive language) and maternal assistance in the process of connecting letter shapes with their sounds during word writing may support the development of children's letter sound knowledge. As letter sound knowledge is strongly related to future reading and spelling ability (e.g., Adams, 1990), it may be beneficial to encourage mothers to scaffold letter shaping and link letters to sounds during joint writing activities. However, as correlation does not imply causation these results might equally be interpreted as the child's level of letter sound knowledge influencing maternal mediation. This could indicate that mothers may be more sensitive to children's letter sound knowledge when scaffolding but not to letter name knowledge or writing ability for which we found no significant relationships. Our finding of no association between letter name knowledge and maternal mediation is in contrast to Aram (2007)'s study where maternal grapho-phonemic and print mediation were both highly correlated with children's letter naming ability. It is possible that the age of the children may affect this relationship as the mean age of Aram's (2007) sample was 5 years 7 months and our sample's mean age was 4 years 3 months. These relationships may emerge later in children's development.

We also did not find any association between name and letter writing ability and maternal mediation. Perhaps the maternal guidance used in writing a shopping list may elicit different scaffolding strategies than name writing. If a joint writing task involved name writing, which is a more familiar word for young children than grocery-related words, it may be possible to find a relationship with the maternal strategies used. Children scored on average almost 5 out of 7 for name writing, evidencing their ability to write part of their name without assistance. This indicated their familiarity with this word, and may explain its independence from the maternal mediation strategies used with unfamiliar word writing. 
Names are also one of the first words young children learn to write (Bloodgood, 1999; Clay, 1975). Thus, the level of writing task difficulty may have affected mothers scaffolding strategies. For example, when mediating children's writing of unfamiliar words mothers may have used more lower level strategies (such as writing the word for the child to copy) in order to scaffold the more difficult task. Furthermore, the age of the children may have influenced the maternal strategies used. Bloodgood (1999) described how 3- to 4-year-olds have weaker motor skills and letter knowledge compared to their older counterparts, which may require mothers to adjust their guidance according to their child's ability.

Only grapho-phonemic mediation was related to print concepts. This result may indicate that mothers were providing higher levels of mediation to children who showed more advanced print concepts such as what letters and words are and how they are directionally positioned on a page. However, as correlation does not imply causation the alternative explanation that the child's level of print concepts shaped the mother's strategies is equally viable. Longitudinal studies are needed to clarify this causal path.

Finally, we found that maternal mediation was not related to children's phonological awareness. This is in contrast to other joint writing studies that found such a relationship (Aram \& Levin, 2001; 2002). Again, the differences in the mean age of the children between Aram and Levin's and our study may have influenced these results. We suggest that the ability to hear rhyme and initial and final sounds in words may not be driving the sort of strategies that mothers use to help younger children produce written letters and words (such as using directional language to shape letters and letter names to label them). Alternatively, maternal scaffolding of writing may not be driving development in phonological awareness and this skill may be more dependent upon developmental factors such as child age or ability in writing and name production. 


\section{Maternal use of environmental print}

Only four mothers used environmental print during the joint writing activity; however, our observational results provided some evidence of innovative uses of environmental print. The environmental print joint writing strategies involved mothers pointing out letters and whole words on product labels (e.g., ICECREAM, LOLLIPOP) or signs (e.g., GROCERY SHOP) for the child to copy. This was supplemented with descriptive and directional language to describe the physical shape of the letter in the environmental print (e.g., I goes straight down). The functional nature of the environmental print also engaged children's interest in the joint-writing task and provided further opportunities for discussions about the print. For example, the attention of one child was initially captured by the picture of icecream on the box. He described it as a hot air balloon then the mother drew his attention to the word. Another mother pointed to the letter I on the icecream box for her child to copy then the child pointed out the letter $\mathrm{C}$ himself and wrote it.

Further analyses comparing mothers who did and did not use environmental print during joint writing showed no differences in the level of maternal print and graphophonemic mediation nor in children's emergent literacy skills, child's age, or family SES. The lack of significant differences may be due to the very small number of mothers that actually used environmental print to scaffold their child's writing. Therefore, although we have provided evidence that some mothers refer to environmental print it is not possible to draw conclusions about the benefits of this behavior for emergent literacy. Nevertheless, the environmental print setting did provide a positive context whereby mothers and children engaged productively in the joint writing task and were observed to enjoy the literacy activity. 


\section{Practical implications and future research}

While most mothers did not use environmental print, the descriptions of those that did provided a glimpse into how mother's used this colorful and meaningful print to engage their child in the joint writing task. As this was not a commonly observed behavior, parents in general may require coaching in using such strategies. Levin \& Aram (2010) showed that coaching mothers in joint writing strategies had a positive effect on the development of children's letter knowledge, phonological awareness, word spelling and decoding. An extension of this research could investigate whether incorporating environmental print into mother-child writing activities enriches these interactions further. Aram (2002) also suggested that home writing activities (e.g., shopping lists, invitations, diaries, notes, recipes and writing signs) are beneficial because they allow mothers to behave more freely and confidently with their children.

Aram (2002) described how activities that were more home-like (writing a list of names of people to be invited to a birthday party) resulted in a joint-writing atmosphere that was warmer and more cooperative than a school-like writing activity. Mothers appeared to be more directive and intrusive (e.g., demanding accuracy for letter shaping) in their mediation of more school-like writing activities. Environmental print could provide a promising tool for these home-like writing activities. For example, mothers could be encouraged to point out environmental print letters and words to their children during joint-writing tasks such as writing notes or a shopping list (e.g., referring to labels on grocery products, toys, or clothing). Environmental print could also be used in writing activities outside the home such as waiting in a bank (e.g., using bank signs to write bank memos), at a restaurant (e.g., using menu boards to write orders whilst waiting for a meal), or in a post-office (e.g., copying postcodes or town names from postal signs onto envelopes). 
In addition, because environmental print is ubiquitous, involving no additional cost to its intended purpose (e.g., food products), and is easy to identify and read, the use of environmental print during joint writing may be beneficial in the teaching of both reading and writing in families from a range of cultural and SES backgrounds. Further research with a more diverse SES sample is required to determine whether maternal use of environmental print strategies during joint writing activities differ across SES. Research that directly manipulates the use of environmental print with a larger sample (for example by prompting mothers and children to use environmental print to help with a literacy task) is needed to determine whether it can foster emergent literacy skills in young children.

Mothers and children in the present study appeared to be engaged in the joint writing task however, it is not possible to determine the degree of enjoyment as this was not measured. Future research could assess enjoyment through a parent-child feedback questionnaire following the joint-writing task in a setting with or without environmental print. This would help determine to what extent an environmental print setting influences joint-writing interactions. Also, the outcomes of using environmental print to support joint writing interactions could be compared with using other print types (e.g., standard print in manuscript form) or other literacy activities (e.g., alphabet book reading). Finally, in order to increase ecological validity it may be necessary to observe parents and children in real-life environmental print settings in the family's home. For example, Cameron \& Pinto's (2009) study of seven 2-year-old girls and their families emphasized the advantages of using video observational methods to record parent-child interactions for a whole day. They reported that detailed analyses of video data that coded for both verbal and non-verbal interactions in the home setting can provide deeper insights into naturally occurring joint literacy activities. 


\section{Conclusion}

The general maternal mediation strategies during joint writing in the present study were similar to those reported in previous studies. However, fewer relationships were found between maternal mediation and emergent literacy skills compared with previous studies.

This may have been due to the younger age of our child participants. We also observed some maternal use of environmental print during joint writing. Due to the few mothers who did this, the benefits of this behavior remains unclear. However, the array of strategies used by this small group of mothers highlights the need for further investigation into the possible advantages of using environmental print to scaffold children's emergent writing. 


\section{References}

Adams, M. J. (1990). Beginning to read: Thinking and learning about print. Cambridge: MIT press.

Aram, D. (2002). Joint writing in Hebrew of dictated words versus proper names: Analysis of low SES mother-kindergartner dyads. Journal of Research in Childhood Education, 17, 47-61.

Aram, D. (2006). Early literacy interventions: The relative roles of storybook reading, alphabetic activities and their combination. Reading and Writing, 19, 489-515.

Aram, D. (2007). Sensitivity and consistency of maternal writing mediation to twin kindergartners. Early Education and Development. 18, 71-92.

Aram, D. (2010). Writing with young children: a comparison of paternal and maternal guidance. Journal of Research in Reading, 33, 4-19.

Aram, D., \& Levin, I. (2001). Mother-child joint writing in low SES sociocultural factors, maternal mediation, and emergent literacy. Cognitive Development, 16, 831-852.

Aram, D., \& Levin, I. (2002). Mother-child joint writing and storybook reading: Relations with literacy among low SES kindergarteners. Merrill-Palmer Quarterly, 48, 202224.

Aram, D., \& Levin, I. (2004). The role of maternal mediation of writing to kindergartners in promoting literacy in school: A longitudinal perspective. Reading and Writing: An Interdisciplinary Journal. 17, 387-409. 
Aram D., \& Biron, S. (2004). Joint storybook reading and joint writing interventions among low SES preschoolers: differential contributions to early literacy. Early Childhood Research Quarterly, 19, 588-610.

Australian Government (2005). National inquiry into the teaching of literacy: Teaching reading, report and recommendations (Publication No. 064277577 X). Canberra, Australian Capital Territory: Author.

Baghban, M. (1984). Our daughter learns to read and write: A case study from birth to three. Newark Delaware: International Reading Association.

Baghban, M. (2007). Scribbles, labels, and stories: The role of drawing in the development of writing. Young Children, 62, 20-26.

Bloodgood, J. W. (1999). What's in a name? Children's name writing and literacy acquisition. Reading Research Quarterly, 34, 342-367.

Bowey, J.A. (1994). Phonological sensitivity in novice readers and nonreaders. Journal of Experimental Child Psychology, 58, 135-159.

Brassard, M. R., Boehm, A. E. (2007). Preschool assessment: Principles and practices. New York: Guildford Press.

Burns, M.S., \& Casbergue, R. (1992). Parent-child interaction in a letter-writing context. Journal of Reading Behavior, 24, 289-312.

Cameron, C. A. \& Pinto, G. (2009). A day in the life. Secure interludes with joint book reading. Journal of Research in Childhood Education. 23, 437-449.

Campbell, R. (1998). A three year old learning literacy at home. Early Years, 19, 76-89.

Clay, M. M. (1975). What did I write? Beginning writing behaviour. Auckland: Heinemann. 
Clay, M. M. (2005). An observation survey of early literacy development. Auckland: Heinemann.

Clay, M. M. (2008). Stones. Rosedale, Northshore: Pearson.

DeBaryshe, B. D., Buell, M. J., \& Binder, J. C. (1996). What a parent brings to the table: Young children writing with and without parental assistance. Journal of Literacy Research, 28, 71-90.

Diamond, K. E., Gerde, H. K., \& Powell, D. R. (2008). Development in early literacy skills during the pre-kindergarten year in Head Start: Relations between growth in children's writing and understanding of letters. Early Childhood Research Quarterly, $23,467-478$.

Dodici, B. J., Draper, D. C., \& Peterson, C. A. (2003). Early parent-child interactions and early literacy development. Topics in Early Childhood Special Education, 23, 124-136.

Dunn, L. M., \& Dunn, D. M. (2007). The Peabody Picture Vocabulary Test (4 ${ }^{\text {th }}$ ed.). Bloomington, MN: NCS Pearson, Inc.

Frith, U. (1985). Beneath the surface of developmental dyslexia. In K. Patterson, J. Marshall \& M. Coltheart (Eds.), Surface dyslexia: Neuropsychological and cognitive studies of phonological reading. (pp. 301-330). London: Erlbaum.

Gerard, M. (2004). What's a parent to do?: Phonics and other stuff. Childhood Education, 80, 159-160. 
Goodman, Y. (1986). Children coming to know literacy. In W. H. Teale \& E. Sulzby (Eds.), Emergent literacy: Writing and reading (pp. 1-14). Norward, NJ: Ablex.

Green, C. (1987). Parents' facilitation of young children's writing. Early Child Development and Care, 28, 129-136.

Harste, J. C., Burke, C. L. \& Woodward, V. A. (1981). Examining our assumptions: A transactional view of literacy and learning. Research in the teaching of English. 18, 84-108.

Hecht, S., \& Close, L. (2002). Emergent literacy skills and training time uniquely predict variability in responses to phonemic awareness training in disadvantaged kindergarteners. Journal of Experimental Child Psychology, 82, 93-115.

Hollingshead, A. B. (1975). The four-factor index of social status. New Haven, CT: Unpublished manuscript. Yale University.

Horner, S. L., (2005). Categories of environmental print: All logos are not created equal. Early Childhood Education Journal, 33, 113-119.

Lass, B. (1982). Portrait of my son as an early reader. The Reading Teacher, 36, 20-28.

Levin, I., \& Aram, D. (2010). Mother-child joint writing and storybook reading and their effects on kindergartners' literacy: an intervention study. Reading and Writing. Published online 16 September 2010. DOI 10.1007/s11145-010-9254-y

Levin, I., \& Bus, A. G. (2003). How is emergent writing based on drawing? Analyses of children's products and their sorting by children and mothers. Developmental Psychology, 39, 891-905. 
Lomax, R. G., \& McGee, L. M. (1987). Young children's concepts about print and reading: Toward a model of word reading acquisition. Reading Research Quarterly, 22, 237256.

Mason, J. M. (1980). When do children begin to read: an exploration of four year old children's letter and word reading competencies. Reading Research Quarterly, 15, 203-227.

Mayer, K. (2007). Emerging knowledge about emerging writing. Young Children, 62, 34-40.

McGee, L. M., Lomax, R.G., \& Head, M. H. (1988). Young children’s written language knowledge: What environmental print and functional print reading reveals. Journal of Reading Behavior, 20, 99-118.

McGee, L. M. \& Richgels, D. J. (1989). “K is Kristen's”: Learning the alphabet from a child's perspective. The Reading Teacher, 43, 216-225.

Miller, L. (1995). "I can read that”. It says "Happy Shopper"- The role of environmental print in early literacy development. Early years, 16, 20-26.

Molfese, V. J., Beswick, J. L., Molnar, A., \& Jacobi-Vessels, J. (2006). Alphabetic skills in preschool: a preliminary study of letter naming and letter writing. Developmental Neuropsychology, 29, 5-19.

Muter, V., Hulme, C., Snowling, M., \& Taylor, S. (1997). Segmentation, not rhyming, predicts early progress in learning to read. Journal of Experimental Psychology, 65, 370-396. 
Neuman, S. B., \& Roskos, K. (1993). Access to print for children of poverty: Differential effects of adult mediation and literacy-enriched play settings on environmental and functional print tasks. American Educational Research Journal, 30, 95-122.

Neumann, M. M., Hood, M., Ford, R. M., \& Neumann, D. L. (in press). The role of environmental print in emergent literacy. Journal of Early Childhood Literacy.

Neumann, M. M., Hood, M., \& Neumann, D. L. (2009). The scaffolding of emergent literacy skills in the home environment: A case study. Early Childhood Education Journal, 36, 313-319.

Neumann, M. M., \& Neumann, D. L. (2010). Parental strategies to scaffold emergent writing skills in the pre-school child within the home environment. Early Years: An International Journal of Research and Development. 30, 79-94.

Pinto, G., Accorti Gamannossi, B., Cameron, C. A. (2011). From scribbles to meanings: social interaction in different cultures and the emergence of young children's early drawing. Early Child Development and Care. 181, 425-444.

Prior, J., \& Gerard, M. (2004). Environnmental print in the classroom: Meaningful connections for learning to read. Newark, DE: International Reading Association.

Puranik, C. S. \& Lonigan, C. J. (2011). From scribbles to scrabble: preschool children's developing knowledge of written language. Reading and Writing. 24, 567-589.

Purcell-Gates, V. (1996). Stories, coupons, and the TV guide: Relationships between home literacy experiences and emergent literacy knowledge. Reading research Quarterly, $31,406-428$. 
Ritchey, K. D. (2008). The building blocks of writing: Learning to write letters and spell words. Reading and Writing, 21, 27-47.

Sinclair, A., \& Golan, M. (2002). Emergent Literacy: A case-study of a two-year-old. Early Child Development and Care, 172, 555-572.

Snow, C. E., Burns, S., \& Griffin, P. (1998). Preventing reading difficulties in young children. Washington, DC: National Academy Press.

Stellakis, N., \& Kondyli, M. (2004). The emergence of writing: Children's writing during the pre-alphabetic spelling phase. Educational Studies in Language and Literature, 4, 129-150.

Sulzby, E., Barnhart, J., \& Hieshima, J. A. (1989). Forms of writing and rereading from writing: A preliminary report. In J. Mason (Ed.), Reading -writing connections (pp. 31-63). Boston, MA: Allyn \& Bacon.

Teale, W. H., \& Sulzby, E. (1986). Emergent literacy as a perspective for examining how young children become readers and writers. In W. H. Teale \& E. Sulzby, (Eds.), Emergent Literacy: Reading and Writing (pp. 7-25). Norwood, NJ: Ablex Publishing.

Tolchinsky, L. (2003). The cradle of culture and what children know about writing and numbers before being taught. Mahwah, NJ: Lawrence Erlbaum.

Vukelich, C. (1994). Effects of play interventions on young children's reading of environmental print. Early Childhood Research Quarterly, 9, 153-170.

Vukelich, C., Christie, J., \& Enz, B. (2008). Helping young children learn language and literacy: Birth through kindergarten. Boston, MA: Pearson. 
Vygotsky, L. S. (1978). Mind and society: The development of higher mental processes. Cambridge, MA: Harvard University Press.

Welsch, J. G., Sullivan, A., \& Justice, L. M. (2003). That's my letter!: What preschoolers' name writing representations tell us about emergent literacy knowledge. Journal of Literacy Research, 35, 757-776.

Whitehurst, G. J., \& Lonigan, C. J. (1998). Child development and emergent literacy. Child Development, 69, 848-872.

Wood, D., Bruner, J. C., \& Ross, G. (1976). The role of tutoring in problem solving. Journal of Child Psychology and Psychiatry, 17, 89-100.

Yamagata, K. (2007). Differential emergence of representational systems: drawings, letters and numerals. Cognitive Development, 22, 244-257.

Yang, H., \& Noel, A. M., (2006). The developmental characteristics of four- and five-yearold preschoolers' drawing: An analysis of scribbles, placement patterns, emergent writing, and name writing in archived spontaneous drawing samples. Journal of Early Childhood Literacy, 6, 145-162. 